\title{
The Purchase and Consumption Motivations of an Organic Product by the Tunisian Consumer: an application on the Prickly Pear Seed Oil (PPS)
}

\author{
Zohra Ghali ${ }^{1}$ and Riadh Hamdi ${ }^{2}$ \\ ${ }^{1}$ Department of sciences of management, ISG of Tunis, Tunis, Tunisia \\ ${ }^{2}$ UAS University
}

Correspondence should be addressed to: Zohra Ghali; zohragh@yahoo.fr

Received date: 26 September 2014; Accepted date: 19 December 2014; Published date: 12 June 2015

Acasemic Editor: Raida Regaieg Essafi

Copyright @ 2015. Zohra Ghali and Riadh Hamdi . Distributed under Creative Commons CC-BY 4.0

\begin{abstract}
This article focuses on the attributes, consequences and values of the consumption of organic products. The study relies on the cognitive chaining method which consists in highlighting and prioritizing the main reasons for purchasing and consuming organic products. A qualitative, exploratory study was conducted involving 60 Tunisian consumers of prickly pear seed (PPS) oil. The results of this analysis show the consumers' associated values which account for the purchase and consumption of organic products (price, health, ethics, satisfaction, local economy, etc.). These values were mainly defined through their cognitive structures. The findings of the research will allow operators to determine areas of improvement of the bio sector.
\end{abstract}

Key words: Bio products, Cognitive chaining, Associated values, Purchase motivations.

\section{Introduction}

The growth slowdown in the sector of organic products stemming from the global economic recession has deeply affected the consumers' purchasing power and their consumption patterns. However, the supply and demand for organic products keep on growing. This is pertaining to the growth related to food security, sustainable development, health, local economy, ethics, etc.
Interest in organic products goes hand in hand with the evolution of the Tunisian society. The field has undergone multiple mutations. This is due to demographic changes, women empowerment, economic growth, diversification of uses, technological innovations, as well as to the globalization of exchanges.

Knowing the main factors leading to buy organic products is certainly crucial in helping firms to better assess the 
consumers' motivations and behavior, so as to market only the products that meet their expectations and needs. Thus, this objective has recently been the focus of several research works and a core interest of several professionals in this sector. Our investigation, conducted within this context, deals with the motivations, consequences and values of bio consumption, and relies on the method of cognitive chaining in an attempt to highlight the motivations in buying and consuming organic products.

Hence, the main objectives of our study are:

- Identifying, theoretically, the main predictive variables (values and motivations) of the decision to purchase organic products, and understanding the meaning of these variables and their effects on the consumer's purchasing intention.

- Analyzing certain perceptions of the buyer of bio products through the cognitive chaining theory.

- Studying the orientations in the consumption / purchase of bio PPS oil.

\section{Analysis of the Consumer's Motivations and Intention to Purchase Organic Products}

Several factors are involved in the consumer's behavior and his selection criteria in purchasing organic products. No doubt, food scare has been created by health crises, namely the mad cow disease, the bird flu, the hazards of the use of the growth hormone and asbestos or global warming.

This current study questions the associated variables can explain the intention and buying behavior involving organic products in Tunisia. These variables are based on the consumer's expectations and motivations.

\section{Motivations in Purchasing Organic Products}

Jolibert \& Baumgartner (1997) define motivation as a state of the individual that determines consumption activities for a specific purpose.

There are numerous motivations drawing consumers towards organic food. Some of them are pertaining to care for the environment and health, others to the promotion of fair trade products and social equity. Economic considerations or a search for a certain flavor are also motivating factors in the purchase of bio food.

As a matter of fact, there are various purchase motivations which converge to determine the consumer's choice of a specific product (Zanoli \& Naspetti, 2002; Baker et al., 2004; Padel \& Foster, 2005; Essoussi \& Zahaf, 2009). A review of the literature shows that consumers adopt a hierarchy of motives following a welldetermined sequencing when buying an organic product, since they believe that biological products are beneficial and richer at the nutritional level than conventional products.

According to Fotopoulos \& Kryskallis (2002) and Wier \& Calverley (2002), the main reason for buying an organic product, as mentioned by consumers, is the better taste of this product since it grew without chemical fertilizers and additives, which also makes it environment-friendly.

According to Davies et al. (1995), the protection of the environment and health constituted the most common argument in favor of buying organic products. Health issues are crucial motivations for purchasing and consuming organic products equally according to Tregear et al. (1994); Magnusson et al. (2003) and Foster \& Padel (2005).

On the other hand, the major concern for health safety has become fundamental in better understanding the attitudes and intentions that determine the purchase of organic products (Magnusson et al., 2001; Magnusson et al., 2003).

We can deduce from the study of Fotopoulus \& Krystallis (2002) that concern for health affects the intention to buy organic products, and is therefore a key source of motivation to consume this type of products.

Tregear et al. (1994) and Schifferstein \& Oude Ophuis (1998) were equally able to demonstrate that concern for health is the 
most important motivation for buying organic products.

Organic products have a potential impact on health. This is certainty rooted in many minds. And a series of scandals has made consumers more aware of what they buy and what they eat.

Buyers and consumers of organic products are particularly driven by value. They can afford to acquire products that guarantee a higher quality compared to conventional products (Tregear et al., 1994; Schifferstein \& Ophuis, 1998 and Naspetti Zanoli, 2002).

Besides, there is a political dimension to consuming organic products. It stems from particular concern for the country of origin of the product, respect for the UN Universal Declaration of Human Rights, willingness to protect the local economy (Honkanen et al. 2006; Ozcaglar-Toulouse et al., 2006) and emphasis on ethical consumption which is inherent in the purchase of fair trade products.

\section{The Intention to Purchase Organic Products}

Lehu (2004) defines purchase intention as "the state of a consumer who declares to be in favor of purchasing a good or a service". As for Monroe \& Krishnan (1985), they stated that "purchase intention is defined as a behavioral tendency leading the consumer to buy the product, and as an important indicator of the actual purchase decision" (Tan, 1999).

Both Azjen \& Fishbein (1981) in their theory of reasoned action and Azjen (1991) in his theory of planned behavior have concluded that the individual's behavior is determined by his intention to accomplish his purchase act. In this case, intention proves to be a lever in predicting the behavior of a person. It should be noted that the prediction variables are the direct antecedent of the purchase behavior, which constitutes the attitude towards the behavior (positive or negative), and the subjective norms (referring to perceived social pressure to perform or not to perform a behavior). A third determinant of intention, called "perception of control over behavior," is whether a person has a positive attitude towards an object, especially when the person is appreciated by those around, and it happens that the person does not adopt this behavior.

The theory of planned behavior has given importance to other factors that influence the intention to perform a behavior, such as external variables, socio demographic variables, personality traits, etc. (Shaharudin et al., 2010). These variables are treated via behavioral, normative and control beliefs.

For Ajzen (1991), the strength of behavioral intention is as important as attitude, subjective norms, and perceived behavioral control.

The outcome of the work of Shaharudin et al. (2010) is in keeping with similar studies despite some differences, among which we cite the identifications of the variables that influence the purchase intention of organic products such as health consciousness, perceived value, concern for food safety and religion. However, it should be noted that within these four factors, concern for religion and food safety are the weakest and show a low correlation with the intention to purchase organic products (Shaharudin et al., 2010).

According to Pernin (2011), the factors having a potential to predict the intention of purchasing organic products are mainly the beliefs in topics related to supporting local producers, environmental benefits, regional identity, and finally identity in relation to organic products. As for other factors (injunctive and descriptive norms, beliefs about the health benefits of local products), they are less significant and the perception of control over behavior is not expressive.

Ahmad \& Juhdi (2010) supported the idea stating that people's belief in favor of food safety in the consumption of organic products explains the positive relationship between health consciousness and the intention to purchase organic food products.

Bigné (1997) established a framework in which green behavior is determined by exogenous variables (such as sociodemographic variables and lifestyle) and 
endogenous variables such as the level of knowledge and environmental skills. For this researcher, the relationship between exogenous variables and endogenous variables gave birth to a new variable called "ecological implication" that will induce biological buying behavior.

\section{Associated Values, the New Levers of Change in Bio Consumption Behavior}

At a time when there is an appeal for the mobilization of personal values to understand consumer behavior, the individualistic side returns to center stage in a difficult socio-political and environmental context, marked by increased competition and a market context that is overall rather gloomy. Within the context of an uncertain environment, knowledge of consumer values and motivations is a tool for a proper understanding of his behavior, which also helps to shed light on the most sensitive segment of this attribute. In the context of organic products consumption, it is interesting to identify some socio demographic, cultural and personal variables, to characterize consumers and to conduct a deeper analysis in which these variables are used to identify and explain the motivations of organic products consumers.

For this, the model of cognitive chaining (means-end chains) by Reynolds \& Gutmann (1988), aims at improving our understanding of consumer behavior by identifying the cognitive structures involved in his decision making process.

\section{The values of Organic Food Consumption}

In psychology, the notion of "values" has several meanings (Rohan, 2000). The term "values" triggers thoughts that are attached to any emotional state, whether pleasant or unpleasant, that the individual experiences (Schwartz, 1992 and Triandis, 1979).

These values draw their origins in the consumer's motivations, as stated by Reynolds and Gutmann (1988). They are considered to be "the expression of the desired existential states" or as a "course of conduct" directing our behavior (Von Heribert \& Stump, 1999). De Ferran (2008) focuses on values that assert the nature of the motivations, in addition to including the consumers' beliefs, attitudes and behavior. In fact, this researcher puts the following idea forward: values influence consumers and drive them towards products that appeal to them; everyone is facing his own emotions and perceptions in order to achieve them fully, that is to say, to reach self-actualization. For Schifferstein \& Ophuis (1998), the consumption of organic products, notably food, refers to life and consumption styles that come from a particular ideological conviction, even from a particular system of values.

"The hedonic dimension influences the commitment to purchase organic products. Therefore, we expect to have more flavor than we can have with conventional products". Here is an additional motivation leading the consumer in the acquisition of his food (Schifferstein \& Ophuis, 1998).

\section{The Usefulness of Personal Value in the Bio Consumer Behavior}

The consumer is a complex individual. His buying behavior varies remarkably according to stimuli, i.e., to personal, social or psychological factors or to the situation. The act of buying is only the visible and perhaps the most pleasant part of a more intricate and difficult decision process, set by the consumer for each purchased product. It is clear that the evolution marking consumer behavior today is based on the individual aspect, as a consequence of the development of information and the lead to alter behavior.

\section{What is the Relationship between Motivations, Values and Product Attributes in the Choice Process?}

Several researchers grant much importance to the links between the motivations, values and attributes of the product in the consumer choice process. For Reynolds \& Gutman (1988), values appear to be the major motivation of consumer behavior.

The importance of identifying values is the subject of growing interest in the Marketing 
research (Pitts 1 Woodside, 1986; ValetteFlorence, 1988).

According to Schwartz and Bilsky (1987 and 1990), value is "the adherence of individuals to objectives, to satisfy interests belonging to these general areas of motivation (...) and which are more or less important in their everyday life". It appears, nonetheless, that the majority of researchers agree on the subject. Similarly, these authors have put forward the differences between the concepts of values and value system, and stipulate that the value system allows bringing knowledge with a level of transparency that is more significant than the individual values related to the motivations that shape and profoundly affect attitudes, beliefs, and consumption behavior. It should be noted that values change and fluctuate on a regular basis during our existence. Vinson, Scott and Lamont (1977) studied the human values related to consumer behavior, and stated the idea that the product's attributes, whether quality or a characteristic, are based on a person's values, and the change in values affects these attributes and behavior. Indeed, the decision to buy is based on a judgment of the value after having evaluated the attributes of the product. In the literature, the notions of motivations and values are a problem the conceptual meaning of which is unclear, and which sheds confusion in the study of these notions. Jolibert \& Baumgartner (1997) and Rokeach (1973) mentioned that we find strong components of motivation in values. Nevertheless, the expression of the values of an individual can be attached to the attributes of a product, more specifically to its symbolic attributes, that is its image, name and design. They are often interpretative elements of the attributes.

\section{Methodology}

\section{Analysis of the Bio Buyer's Perceptions through the Cognitive Chaining Theory}

Any behavior implies that the consumer makes decisions. These can be simple, or be the result of a complex chain of activities, the objective of which is action planning or object design. We opted for the adoption of the theory of thin medium chains, insofar as the product attributes are known and the anticipated consequences are most favorable. Thereafter, by detecting the values, we compare them and organize them along the consumers' preferences, while exposing a hierarchical map which will allow to better discriminating facts and values. The central theme consists in dealing with questions relating directly to the understanding and identification of the set of associations mentioned by the interviewees in a survey about the links between the various hierarchical levels related to a product: its characteristic attributes, the benefits it brings to the buyer, and individual values associated by consumers with the purchase / consumption of this product.

In order to make the theory more explanatory, we use the laddering method which consists in highlighting three levels whose main elements are Values (V), Consequences (C), and product Attributes (A), as indicated by Valette-Florence et al., (2003).

Therefore, a set chain reflects a link between three levels:

\section{Attributes $\rightarrow$ Conséquences $\rightarrow$ Values.}

We will use the method of written protocols, also called hard laddering, as determined by Walker and Olson (1991). This method was widely used in analyzing consumer food choices.The hard laddering method relies on a self-administered questionnaire in the form of a set of specific questions.

After determining the salient features of bio PPS oils, the respondents list the attributes in order of importance, and then fill in the next column, explaining why the selected element is important for their choice (De Ferran, 2006). To make the interview easier, we will establish a panel of attributes, consequences and values that is previously generated. Respondents will make their choices in this list (Annex 1).

The theory of cognitive chaining implies that consumers make their purchase decision in a willful and conscious way. It shows the relevant factors of the consumer decision- 
making process, while explaining the meaning they associate with the products. Indeed, such links are chains of subjective associations and are presented in a hierarchical map.

\section{Sampling}

Our exploratory research relies on the realization of sixty semi-structured interviews with consumers of organic PPS oils.

Interviews were conducted in two regions: Sidi Bouzid and Tunis, the capital.

Our sample consists of consumers belonging to a predetermined socio-demographic profile: young, educated, having a high income, living in major urban areas, conscious about health and quality, deeply involved in the purchasing process of highquality organic oils, and holding a wide set of reasons and personal values associated with the purchase of this product.

As part of this research, we opted for a reasoned random sample that could be considered as sampling by particular judgment (Malhotra, 2004). It consists in identifying a number of descriptive features in the targeted population, which the researcher will respect in his sample.

Women make up the targeted population for two main reasons: first, women highly value body care. On the other hand, they show a more dynamic engagement than men do in militant movements for the preservation of the environment. They have, thus, an increased tendency to consume organic products.

\section{Data Collection}

It was conducted along two stages. First, we held a ninety-minute meeting in a room with a homogeneous group of ten people (focus group) (Annex 2), to generate a nonexhaustive list of attributes, consequences and values associated with the consumption of organic essential oils. This same list was used as a support for individual interviews.

Meetings were held in an open way in the absence of a questionnaire.
Particularly, the interviewer would ask the respondent to say why certain attributes of organic PPS oil are important to him. As the questionnaire is not prescriptive, these attributes are chosen by the respondent himself.

The interviewer asks the following opening question: "Can you tell us what motivated you to buy organic PPS oil?" In order to launch the debate, the following question comes next: "Tell us why this seems important to you?"

In order to make the content as pertinent as possible to the objectives of the research, we carry on asking the group members the following: "This is certainly not the only reason why you bought the bio PPS oil rather than another one?"

In a second step, we conducted a questionnaire (Annex 3) to establish the medium thin chains mentioned earlier. We started from a list that was predetermined during the group meeting (focus groups), and asked interviewers to complete it.

The interview protocol was to be performed in three steps, listed as follows:

Step 1: Using the list of bio PPS oil attributes, we ask the interviewee to choose an item that he deems paramount in the buying process.

Step 2: We ask him to select within the set of the most important consequences, one that is directly related to the selected attribute. This link represents the characteristics that can most lead to the satisfaction he expects from the attribute selected previously.

Step 3: Depending on the choice of a term mentioned in the list of consequences, the interviewee selects an item that appears to him crucial from the list of personal values. This relation confirms the higher expectation and the aspiration that is most sought through this satisfaction.

Thus, we see a strong association between an attribute of a product and the functional or psychological consequences, as well as the resulting values.

To summarize, a first chain is therefore formed, and so on until the interviewee is 
able to detect three other attributes that is three new original chains.

\section{Interpretation of Results}

\section{Illustration of Results}

An analysis based on hierarchical cards allowed to establish a certain representation of the structure of cognitive chaining, while uniting the most commonly cited attributes with the consequences with a high percentage of associations; the same was done for the interactions between values and consequences.

Figure 1 illustrates a hierarchical map wherein all relations are represented. Reading this card is done by starting from an attribute and going up to the values. A consumer could direct his choice towards bio PPS oil, for instance. Depending on its origin, the product will be trustworthy and raise a feeling of satisfaction in the consumer.

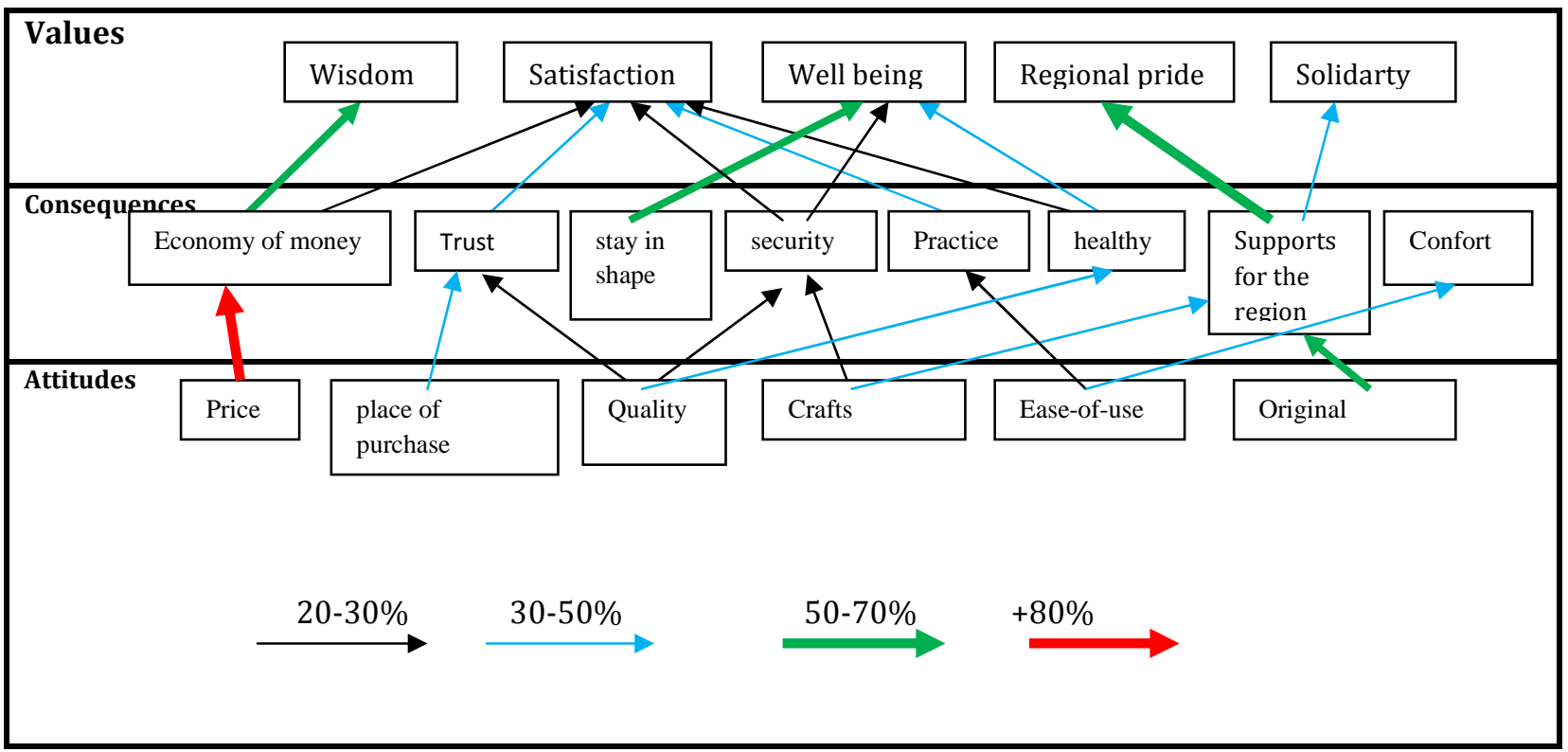

Figure 1: Outline map of consumers of organic PPS oil

\section{Guidelines in the Consumption / Purchase of Organic PPS Oil}

Findings highlight five possible orientations of consumers / buyers of organic PPS oils. Some of these orientations, said dominant, report a mixed motivation (individual or collective)

- The first dominant orientation shows the underlying value of the consumption of bio PPS oils. It is led by the sought value of "wisdom" (Figure 1), which originates in the rational and calculated behavior "saving money", that is in turn associated with the attribute of "price".
However, in these times of constant economic crisis, consumers / buyers are watching their budgets and spending, by seeking ways to spend their money more wisely, that is by getting the maximum pleasure in the short run and happiness in the long run, reducing expenses and risks, avoiding regrets, and making the right financial decisions.

- The second main thrust of the purchase of bio PPS oil is regional pride. It leads to the production of the most represented cognitive chain structure, extracted by the analysis of this type of consumption, which appears as engaged consumption. 
The major links of the main chain connect "regional pride" to the extrinsic attribute of bio PPS oils, namely the "origin of the product", through the benefits of "support for the region" which promotes strong participation in an alternative economy for small producers and contributes to the overall promotion of the region.

- The third direction is the interest related to well-being that is shown by some respondents via a structure that joins the consequence: "healthy". It is associated with the determining attribute that allows an assessment of bio PPS oil, namely "quality".

- The fourth direction focuses on the value of "satisfaction". The structure of cognitive chaining shows a direct link with the attribute "point of purchase" of bio PPS oil. The vocation "origin of goods" of the bio PPS oil emphasizes respect of the environment and living beings by offering an advantage in terms of safety, that consists in not using synthetic chemical treatments, pesticides or GMOs. Therefore, bio PPS oils are healthy products and consumers/buyers feel reassured and confident when buying them. The latter are, indeed, more and more attentive to the product composition and ingredients and to the origin and the place of production.

- The fifth orientation, that is more marginal, is cited by respondents through a structural equation joining the attribute "artisanal" to the consequence "support for the region" in a perspective of "solidarity". That being said, by supplying himself locally the consumer / buyer supports farms and stimulates the local economy. This action contributes to the sustainability of the activity in addition to helping in the creation and protection of jobs and to creating a know-how which is an asset to the cultural life of the region. It is in this context that consumers / buyers prove to be more supportive and working to improve the producers' incomes, to protect and conserve natural resources, and to integrate agriculture in the national and international markets.

- The sixth main motivation in the purchase of PPS oil comes from the sought value "satisfaction", which springs from "confidence", and can really constitute a guarantee that consumers will not be cheated. Confidence is strongly associated with the "point of purchase". In fact, buying directly from the producer, without intermediaries, allows to strengthen the bond of trust between the producer and the consumer and to create a sense of belonging.

In general, the opportunity to buy bio PPS oil is offered through various distribution channels. Thus, trust in the producers and traders is the reason that most often leads customers to shop from these purchase point, where contact is warm, friendly and professional.

Similarly, we notice the presence of a minor chain in which consumers seek to reach a degree of "satisfaction" that appears in some interviewees following a lived experience and an expectation, through a chain uniting the consequence "practical / functional " to the attribute " ease of use ".

Indeed, it seems essential that consumers of PPS oil also grant more importance to ease of use that is made possible by some ergonomic grip which provides optimal fit between the product's weight, size, shape and right dosage to limit loss.

The results of the focus groups show that PPS oil consumers prefer glass bottles with a pump and airless bottles. PPS oil integrates innovation and design to bring prevention and treatment solutions that do not rely on drugs and that focus on user comfort. The consequence "practical / functional" is frequently sought for its skin regeneration capacity. The oil is used for hair care as well as for dry and wrinkled skin care. It is equally an anti-diabetic product.

This chain shows that moderate and occasional consumers are more motivated by the search for "satisfaction" than by social or altruistic values.

The dominant orientations presented in the following sequences show mixed or heterogeneous motivations and take a rather hedonistic individual nature:

"Quality" $\rightarrow$ "Healthy" $\rightarrow$ "well-being" 
On the other hand, it takes a collective nature that is more socially-oriented, as indicated by the following structural formula: "artisanal" $\rightarrow$ "support for the region" $\rightarrow$ "regional pride."

It should be noted that the structure "Keeps you fit" $\rightarrow$ "well-being" is distinguished by the non-existence of a direct link between the attribute and the value that gives a more or less symbolic character to the purchase act.

Finally, the structure "ease of use" $\rightarrow$ "comfort", considered as a benefit sought by consumers of organic PPS oils, is not attached to any value. Therefore, we believe that comfort is certainly a value.

The results of the study conducted on the main directions of PPS oils consumption show similarities with the findings of studies on the motivation related to the consumption of organic food (Naspetti \& Zanoli, 2002; Baker et al., 2004;. Padel \& Foster, 2005). That is to say that consumers / buyers of PPS oils would be more sensitive by the collective nature of motivation and the more hedonistic search for individual well-being.

\section{Conclusion, Contributions, Limitations and Future Research Tracks}

In order to spot trends and identify the particular features of motivation for the Tunisian consumer, a literature review is conducted to contribute to the understanding of the theme of organic products.

Tunisian consumers base their purchasing decisions of organic products on their own perceptions of the values resulting from these products.

The values associated with consumer behavior take into account not only the quality/price ratio, but also the way the product is inscribed in the culture, lifestyle, social awareness and the intellectual level of the consumer.

This research led us to consider that the intention of buying organic products depends on behavior which is a precursor of the final purchase level of the biological product. Therefore, the intention to act depends on the attitude and on favorable subjective norms, as well as on the perceived behavioral control.

To conclude, we can say that this research has a two-fold contribution. First, at the academic and theoretical levels, it tackles a deeply interesting subject, which represents a major concern for many consumers and firms, namely biological consumption. Indeed, nowadays there are several attempts seeking to better theoretically analyze consumer behavior towards organic products, and to identify the factors of influence and the values associated with this product category. In the Tunisian context, there is not yet, in our view, any academic work that deals with this subject in the same field of study. Then, at the professional and managerial levels, this work highlights the factors that can influence the purchasing behavior and the consumption of an organic product, which will allow professionals operating in this sector to act in a more efficient way and to adjust their marketing actions. In fact, according to our empirical results, the Tunisian consumer has a rational and well-thought behavior when it comes to purchasing an organic product. He seeks cheaper price but better quality for a product that satisfies his needs and meets his expectations. These different variables urge professionals working in the organic sector to control the production and marketing costs of their products. Similarly, the fact that the origin of the product is taken into consideration in the purchasing decision invites professionals to carefully select the market for each product according to its origin, since the results show that the customer is more confident and grants more credibility to a product when he knows its origin and source.

In the end, we would like to refer to two limits of this research. First, insufficient bibliographical resources on this topic prevented us to compare our findings with those of previous works conducted in similar contexts. Besides, we found it difficult to contact all the customers of PPSoil-producing firms due to the absence of a 
database. Our ambition, though, is to conceptualize the relationship between the variables investigated in this study and those dealt with in other research works, so as to determine which associated variables influence the Tunisian consumer's purchase intention of an organic product.

\section{References}

1. AjzenIce, K. (1991). The theory of planned behavior. Organizational Behavior and Human Decision Processes, 50, 179211.

2. Bigné, J.E. (1997). Cited in A. Gracia \& T. de Magistris. (2007). Organic food product purchase behavior: A pilot study for urban consumers in the south of Italy. Spanish Journal of Agricultural Research, 5, (4), 439 451.

3. Davies, A., Albert J. Titterington \& C. Cochrance. (1995).Who buys organic food? A profile of the purchasers of organic food in Northern Ireland. British Food Journal, 97, (10), 17-23.

4. Davies, C., B. Lazell, M. Hughes, \& L. Cooper. (1995). Time is just another attribute - or at least, just another dimension. Clifford and Tuzhilin, 1, 175-193.

5. Essoussi, H. \& M. Zahaf. (2009). Exploring the decision-making process of Canadian organic food consumers. Motivations and trust issues. Quantitative market research. International Journal, 12(4), 443-459.

6. Fishbein, M. \& I. Ajzen. (1981). Attitudes and voting behavior: An application of the theory of reasoned action. Cited in AjzenIcek. The Theory of planned behavior. Organizational Behavior and Human Decision Processes, 50, 179- 211.

7. Fotopoulos, C. \& A. Krystallis. (2002). Purchasing motives and profile of the Greek organic consumer: A countrywide survey. British Food Journal, 104, (9), 730- 765.

8. Honkanen, P., B. Verplanken \& S.O. Olsen. (2006). Ethical values and motives driving organic food choice. Journal of Consumer Behavior, 5, 420-430.
9. Jolibert, A. \& G. Baumgartne. (1997). Values, motivations and personal goals: Revisited. Psychology and Marketing, 14 (7), 675-688.

10.Kilmann, R.H. (1981). Toward a unique/useful concept of values for interpersonal behavior: A critical review of the literature on value. Psychological Reports, 48, 939-959.

11.Magnusson, Maria K., A. Arvola, H. Koivisti, L. Ulla-Kaisa Aberg \& P.O. Sjodén. (2003). Choice of organic foods is related to perceived consequences for human health and to environmentally friendly behavior. Appetite, 40, 109- 117.

12.Magnusson, Maria K., A. Arvola , Koivisto Hursti U-Kaisa \& L. Aberg. (2001). Attitudes towards organic foods among Swedish consumers. British Food Journal, 103(3),209- 227.

13.0zcaglar-Toulouse, N., E. Shiu, D. Shaw. In Search of fair trade: ethical consumer decision-making in France. (2006). International Journal of Consumer Studies, 30, 502-14.

14.Padel, S. \& C. Foster. (2005). Exploring the gap between attitudes and behavior: Understanding why consumers buy organic food. British Food Journal, 107, (8), 606-625.

15.Pitts, R., \& A. Woodside. (1986). Personal values and travel decisions. Journal of Travel Research, 25(1), 20-25.

16.Reynolds, T.J. \& J. Gutman. (1988). Laddering theory, method, analysis, and interpretation. Journal of Advertising Research, 28, 11-31.

17.Schifferstein Hendrik, N.J. \& A.M. Oude Ophuis Peter. (1998). Health-related determinants of organic food consumption in the Netherlands. Food Quality and Preference, 9, (3), 119- 133.

18.Schwartz, S.H. (1992). Universals in the content and structure of values: Theoretical advances and empirical tests in 20 countries. In M. Zanna (ed.), Advances in Experimental Social Psychology, 25, 1-65. 
19.Schwartz, S. H. \& W. Bilsky. (1987). Toward a universal psychological structure of human values. Journal of Personality and Social Psychology, 53, 550-562.

20.Schwartz, S. H. \& W. Bilsky. (1990). Toward a theory of the universal content and structure of values: Extensions and cross-cultural replications. Journal of Personality and Social Psychology, 58, 878891

21.Shaharudin, M.R., J.J. Pani, S.W. Mansor \& S.J. Elias. (2010). Purchase intention of organic food: Perceived value overview. Canadian Social Science, 6, (1), 70- 79.

22.Siti, A., \& Bayaahet Juhdi Nurita. (2010). Organic food: A study on demographic characteristics and factors influencing purchasing intention among consumers in Klang. International Journal of Business and Management, 5, (2), 105- 118.
23.Tregear, A., M.J. Dent \& Mc Gregor. (1994). The demand for organically grown produce. British Food Journal, 96(4),21-25

24.Vinson, D.E., J.E. Scott \& L.M. Lamont. (1977). The role of personal values in marketing and consumer behavior. Journal of Marketing, 14, 44-50.

25.Von Heribert, G. \& S. Stumpp. (1999). L'influence des convictions de contrôle et des attitudes globales sur le comportement écologique du consommateur. Recherche et Applications en Marketing, 14 (2), 71-83.

26.Walker, B. \& J. Olson. (1991). Means-end chains: connecting products with self. Journal of Business Research, 22, 111-118.

27.Wier, M. \& Calverley. (2002). Market potential for organic foods in Europe. British Food Journal, 104(1), 45- 62.

28.Zanoli, R. \& S. Naspetti. (2002). Consumer motivations in the purchase of organic food. British Food Journal, 104(8), 643-653.

\section{Books}

Lehu, J. M. (2004). L'encyclopédie du marketing, Editions d'Organisation, Paris, p.955.

Malhotra, N., J.M Décaudin \& A. Bouguerra. (2004). Etudes marketing avec SPSS. Paris: Pearson Education.

Monroe, K.B. \& R. Krishnan. (1985). The Effect of Price on Subjective Product Evaluations. Jacob Jacoby \& C. Jerry Olson in Perceived Quality: How Consumers View Stores and Merchandise. Lexington Books.

Rokeach, M. (1973). The Nature of Human Values. Free Press: New York .

Triandis, H.C. (1979). Values, attitudes, and interpersonal behavior, Nebraska Symposium on Motivation: Beliefs, Attitude, and Values. Lincoln, Nebraska.

\section{Conference Paper}

De Ferran, F. (2008). «Les déterminants à l'achat de produits issus du commerce équitable en GMS : une approche par les chaînages cognitifs », Actes du 24ème Congrès International de l'Association Française du Marketing, Paris.

De Ferran, F. (2006). « Comparaison de trois techniques de collecte des chaînages cognitifs dans le cadre du choix d'un produit socialement désirable : le café issu du commerce équitable", Communication présentée à l'EMAC.

Pernin, J-L. (2011). "L'intention d'achat de produits biologiques régionaux: une recherché exploratoire sur la base de la théorie du comportement planifié". Université de Toulouse, IUT de Tarbes, Colloque : Les transversalités de l'agriculture biologique, Strasbourg (23 end 24 June).

\section{Online Journals and Websites}

Valette-Florence, P. (1988). L'implication, variable médiatrice entre styles de vie, valeurs et modes de consommation. Thèse pour le Doctorat Sciences de Gestion, Université Pierre Mendès-France, Ecole Supérieure des Affaires, Grenoble. 
Annex

Annex1: Table 1: List of attributes, consequences and values generated

\begin{tabular}{|l|l|l|}
\hline \multicolumn{1}{|c|}{ A. attributes } & \multicolumn{1}{|c|}{ B. Consequences } & \multicolumn{1}{c|}{ C. Values } \\
\hline $\begin{array}{l}\text { Price } \\
\text { Origin of the product } \\
\text { Place of purchase }\end{array}$ & Healthy & Srust \\
Aspect & Allows you to stay in shape & Wellness \\
Texture & Respect for the environment \\
Craft & Save money & Wisdom \\
Quality & Solidarity \\
Ease of use & Comfort & \\
& & \\
\hline
\end{tabular}

Annex 2: maintenance of the focus study Guide

\section{Group I. study Cognitive}

Question 1: can you tell us what pushed you to buy prickly pear seed oil of barbarism?

Question 2: what is organic prickly pear seed oil for you?

Question 3: Tell us, why you think important?

Question4: this is certainly not the only reason for which you have purchased organic prickly pear seed oil rather than another?"

Question 5: What manner of presentation of prickly pear seed oil of barrel do you prefer?

? Glass vials $10 \mathrm{ml}$ to $100 \mathrm{ml}$

? 15 to $50 \mathrm{ml}$ spray vials

? Bottle glass + pump 100-200 ml

? Airless bottle15-50 ml

? 10 to $20 \mathrm{ml}$ pot

Question 6: What are your purchasing criteria?
Well being
Efficiency of products
The quality/price ratio

Zohra Ghali and Riadh Hamdi (2015), Journal of North African Research in Business, Article ID 220428, DOI: $10.5171 / 2015.220428$ 
- The respect of the nature of the environment The quality of the products (appearance, metabolism...)

Question 7: On average, how often do you consume prickly pear seed oil?
2? Once a day
? At least once a week
?. At least once a month
? More occasionally

Question 8: What is the type of your consumption PPS oil of figs?

?Tradition ?Before the holidays ?Seasonal ?Out of habit

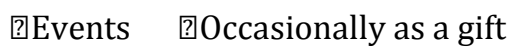

\section{Emotional study}

Question 1: What is the important attributes prickly pear seed oil of figs?

Question 2: What are your primary motivations of purchasing prickly pear seed oil of barbarism?

Question 3: what is your best satisfied in prickly pear seed oil of barbarism?

Identification responder (e) -

Genre: ? man ? women -

Age group: ? 20-30 years ? 31-50 years ? > 50 years -

Level of study: ? secondary ? University - undergraduate ? ? ? ? University - graduate ?Vocational training

\section{Socio-professional class}

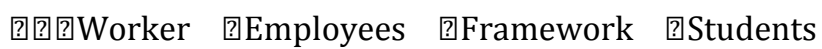

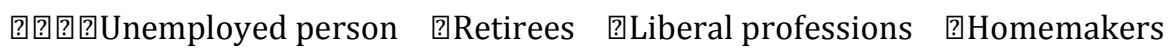

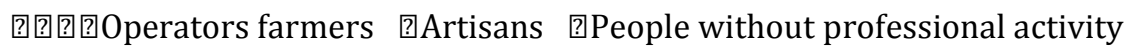

? Other:...

\section{-Monthly net income of the household}

? $<500$ Tunisian dinars 


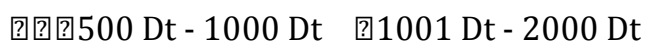

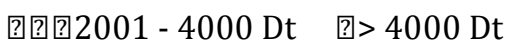

\section{Annex 3:}

\section{Questionnaire}

Question1: Where do you buy PPS oil? (Several answers possible)

? ? ? ? ? Large surface ?To the market ?At a nearby merchant

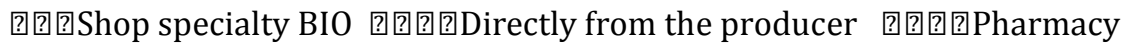

?2? ? Parapharmaceutical ?On the internet

Question 2: What is the type of your consumption PPS oil?

?Tradition ?Before the holidays ?Seasonal ?Out of habit ?Events

? Occasionally as a gift

Question 3: How often do you use at least them oil barrel Bio of seeds of figs?

? Once a day ?At least once a week ? At least once a month

?More occasionally ?Never

Question 4: Has what greenhouse oil barrel Bio of seeds of figs?

?Hair care ?Body care ?Facial ?Diabetes ?Weight loss

?Relaxing ?Anti-stress? For physical pain ?For the emotions

? For digestion ? ? ? Sleep ? good cicatrisant

Question 5: What are your motivations for consumptionoil barrel Bio of seeds of figs?

? Health, well-being... ? The respect of the nature of the environment...

? The quality of the products (appearance, metabolism...) ? Products the quality/price ratio

Question 6: Using the list below, choose the four criteria most important to you and prioritize descending when shopping oil barrel Bio of seeds of figs:

\begin{tabular}{|l|l|l|}
\hline $\begin{array}{l}\text { Select an item that feel you the } \\
\text { most important in the list has } \\
\text { Why is it important for you? }\end{array}$ & $\begin{array}{l}\text { Depending on the choice of an } \\
\text { element, select an item that you } \\
\text { believe is important among the } \\
\text { elements of list B }\end{array}$ & $\begin{array}{l}\text { Depending on the choice of a } \\
\text { Belement, select an item that } \\
\text { you believe is important } \\
\text { among the elements of list C }\end{array}$ \\
\hline
\end{tabular}

\section{Example:}




\begin{tabular}{|l|l|l|l|l|}
\hline Quality & ? & healthy & $?$ & Satisfaction \\
\hline
\end{tabular}

I chose the quality as important for me. Essential oils are healthy products, which finally gives me satisfaction.

\begin{tabular}{|c|c|c|c|c|c|}
\hline & A. attributes & & B. Consequence & & C. value \\
\hline 1 & & ? & & ? & \\
\hline 2 & & ? & & ? & \\
\hline 3 & & ? & & ? & \\
\hline 4 & & ? & & ? & \\
\hline \multicolumn{2}{|c|}{ A. Attributes } & \multicolumn{2}{|c|}{ (B). Consequences } & \multicolumn{2}{|c|}{ C. Values } \\
\hline \multicolumn{2}{|c|}{$\begin{array}{l}\text { Price } \\
\text { Origin of the product } \\
\text { Place of purchase } \\
\text { Aspect } \\
\text { Texture } \\
\text { Craft } \\
\text { Quality } \\
\text { Ease of use }\end{array}$} & \multicolumn{2}{|c|}{$\begin{array}{l}\text { Healthy } \\
\text { Trust } \\
\text { Allows you to stay in shape } \\
\text { Respect for the environment } \\
\text { Save money } \\
\text { Support for the region } \\
\text { Comfort }\end{array}$} & \multicolumn{2}{|c|}{$\begin{array}{l}\text { Satisfaction } \\
\text { Wellness } \\
\text { The regional pride } \\
\text { Wisdom } \\
\text { Solidarity }\end{array}$} \\
\hline
\end{tabular}

Question 7: What is your sex?

?. man ? ? woman

Question 8: What age group do you belong to?

?? ?hess than 25 years ?Between 25 and 34 years ?Between 35 and 44 years ?Between 45 and 54 years ? More than 55 years

Question 9 What is your highest degree?

? ? ? ? ? ? University - undergraduate ? ? University - graduate

?ㄴ? Vocational training ? ?0ther (specify)

Question 10: What is your current employment status?

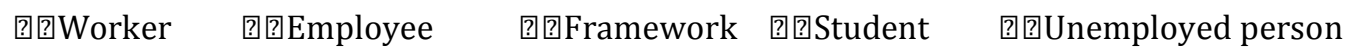

? ?Retirement ? ?Liberal profession

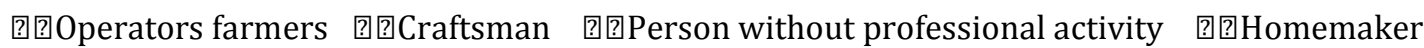

\section{Question 11: In what monthly income bracket is located your home?}

?? ?Less than 500 Tunisian dinars ? ?500 Dt to $1000 \mathrm{Dt}$

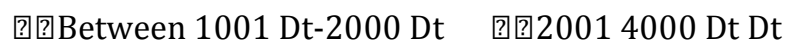

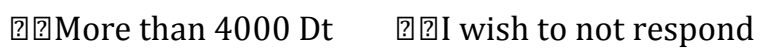

Question 12: Number of permanent people living in the household including you.

Number of persons at home: including children: 